\title{
Research Paper: \\ Resilience and Emotional Reactions to Failure Mediated by Self-compassion and Emotion Regulation in Martial Artists
}

\author{
Mahmoud Mohebi ${ }^{1}$ (D), Hassan Gharayagh Zandi ${ }^{1 *}$ (D) Mohammad Ali Besharat $^{2}$ (D), Mahboubeh Ghayour Najafabadi ${ }^{1}$ (C)
}

1. Department of Motor Behavior and Sports Psychology, Faculty of Physical Education and Sport Sciences, University of Tehran, Tehran, Iran. 2. Department of Health Psychology, Faculty of Psychology and Educational Sciences, University of Tehran, Tehran, Iran.

$\begin{gathered}\text { use yur devic to scan } \\ \text { and read thearticle online }\end{gathered}$
$\begin{aligned} & \text { Ure Mediated by Self-compassion and Emotion Regulation in Martial Artists. Journal of Exercise Science and Medicine. 2020; } \\ & \text { 12(1):113-124. http://dx.doi.org/10.32598/JESM.12.1.12 }\end{aligned}$
dolihttp://dx.doi.org/10.32598/JESM.12.1.12

Article info:

Received: 19 Sep 2019

Accepted: 13 Dec 2019

Available Online: 01 Jan 2020

Keywords:

Resilience, Reactions to failure, Self-Compassion, Emotion regulation, Recovery from failure

\section{A B STRACT}

Introduction: The present study aimed to examine a proposed model for the relationship between resilience and emotional reactions to failure, mediated by self-compassion and Emotion Regulation (ER) among martial artists.

Materials and Methods: A total of 286 athletes (191 males \& 95 females; Mean \pm SD age: $20.98 \pm 3.30$ years) from different disciplines of martial arts (taekwondo, karate, Judo, \& wushu) engaged in league championship participated in the study. Athletes completed the Sports Mental Toughness Questionnaire (SMTQ), the Positive and Negative Affect Schedule (PANAS), the Self-Compassion Scale (SCS), and the Cognitive Emotion Regulation Questionnaire (CERQ). The proposed model was evaluated using structural equation modeling.

Results: The obtained results revealed that resilience has direct and indirect effects on emotional reactions to failure. Furthermore, self-compassion and maladaptive ER play a partial negative mediating role between resilience and emotional reactions to failure. However, the mediating role of adaptive ER was not significant.

Conclusion: The study data predicted negative emotional reactions to failure based on resilience, mediated by self-compassion and ER among martial artists; thus, these data indicate the necessity of paying attention to the development of resilience in martial artists. This method emphasizes self-compassion and the reduction of maladaptive ER for better recovery of failure and reduces its effects.

* Corresponding Author:

Hassan Gharayagh Zandi, PhD.

Address: Department of Motor Behavior and Sports Psychology, Faculty of Physical Education and Sport Sciences, University of Tehran, Tehran, Iran. Tel: +98 (21) 61118915

E-mail: ghzandi110@ut.ac.irorchid 


\section{Introduction}

ailure is a major challenge for athletes with high-performance levels [1]. The stress that athletes experience when encountering failure is psychological $[2,3]$. Previous studies indicated that approximately $80 \%$ of Olympic athletes and $34 \%$ of elite swimmers who failed in their sport experienced the symptoms of major depressive disorder [4, 5]. This finding is important, as failure experiences may impair athletes' mental health [5-7]. Furthermore, when failures occur, individuals become more vulnerable to future failures and perform poorly [8-10]. Failure may also impose high physiological costs on the athlete by increasing the autonomic system arousal and affecting their physical health [11]. In other words, failure is associated with a negative emotional response, avoidance, and fear of failure $[7,11,12]$. Moreover, numerous athletes feel self-deprecation and emotional distress after a failure $[1,12,13]$. Such negative responses to failure can be unconstructive and impair self-regulation, emotional recovery, stress management, and performance $[6,14$, 15]. Thus, the path to success taken by numerous elite athletes is based on their ability to constructively respond to problems, like a failure [16]. Researchers found that experiences, such as failure are inevitable features of participating in sports. However, how athletes evaluate failure, react to it, and regulate their emotions determines the outcome of such events $[11,17]$.

Resilience is an essential psychological trait that affects how a subject copes, reacts, and evaluates difficulties and perseverance in achieving goals [18]; this component seems to be involved in the process of coping with competition problems, like a failure. Athletes who are constantly striving to reach the best or the desired level of their athletic performance, regardless of the situation (i.e., positive \& negative situations) and context (i.e., training \& competition), are often described as mentally strong [19]. According to prior research [20], resilience facilitates adaptive responses to the positive and negative demands of exercise during training and competition to achieve one's goals. Besides, in the case of failure, it enables the individual to manipulate failure to return to optimal performance.

Studies $[21,22]$ suggested that paying attention to the aspects of resilience in different situations leads us to a deeper understanding of how this construct works. Surprisingly, research that can examine the role of resilience in failure manipulation and subsequent emotional adjustment is scarce. Although this feature indicates that individuals have high emotional control, relevant studies on emotions are often inductive and rely on emotional experiences as well as responses expected from resilient athletes $[18,20,23]$. Besides, when studies directly measured post-competitive emotion states [24, $25]$, the results were reported as combined (regardless of win or loss). Thus, negative emotional reactions that athletes with resilience experience are less well-known, especially at the time of failure. Moreover, the role of this trait in adapting to failure conditions and emotional problems remains undiscovered.

Another critical characteristic characterized by the desire to reduce individual suffering in times of difficulty is self-compassion [6]. This psychological concept has recently drawn the attention of clinical and sports psychology; it has been conceptualized based on a positive psychology framework [26]. Self-Compassion consists of 3 main components, as follows: being kind and selfperception (instead of criticizing), understanding personal problems and misfortunes as common humanity (instead of feeling isolated \& suffering), and maintaining a balanced and open view of the problem (rather than over-identification \& drowning in it) [27]. Empirical evidence signifies that a state of self-compassion makes individuals more responsible for their role in negative events, viewing shortcomings as changeable, and become more motivated to change $[3,28]$.

Resilience and self-compassion were theorized as adaptive coping processes [26], psychological well-being promoter $[6,25]$, and inhibitor of depressive symptoms, stress, and anxiety $[6,25]$; however, very limited research has examined the direct relationship between resilience and self-compassion in the general literature, especially sports. In support of this view, Mahmoud and Sahar [29] argued that elite adolescent taekwondo athletes had higher resilience and self-compassion, compared to non-elite taekwondo athletes; it can potentially inform the route of relationship among the constructs to each other and key variables (e.g., performance). Crust and Azadi [30] stated that mentally tough athletes use more self-talk skills. Wilson et al. [26] found that self-compassion is a positive form of self-talk in difficult situations. Therefore, mentally tough individuals, because of their ability to be self-compassionate, adapt more easily to difficult situations, like a failure. In particular, a laboratory study found that self-compassion could accelerate athletes' emotional recovery in the failure scenario, whereas fear of self-compassion was associated with negative thoughts about failure [11]. 
Another mechanism associated with emotions is Emotion Regulation (ER). ER is an intrinsic aspect of emotional response tendencies and refers to strategies used to reduce, increase, or maintain emotional experiences to cope with stressful situations [31]. In the face of stressful events, individuals use different ER strategies to modify their emotional experiences [31].

Researchers have identified two categories of cognitive strategies, as follows: first, adaptive ER strategies, including positive refocusing, positive reassessment, acceptance, putting into perspective, focus on planning; second, less adaptive strategies, including self-blame, blaming others, rumination, and catastrophizing, both of which will have their consequences [32]. However, the outcome of different ER strategies may depend on the context. For example, cognitive reassessment strategies are less adapted when stressors are manageable [33]. Some research has provided preliminary evidence on how individuals with resilience regulate their emotions in daily life [34, 35]. However, there no research examined the types of ER strategies applied by individuals with resilience in stressful situations. Besides, resilience is strongly related to ER in these situations. Moreover, there exist 3 main reasons for this expectation. First, in resilience models, emotion control is considered among the main dimensions, and the validity of this inclusion has been supported by several researchers [18, 23, 36].

Mental strength is closely related to self-regulation in a broader context and allows individuals with resilience to succeed in adverse conditions [37]. Finally, Nicholls, Polman, Levy, and Backhouse [38] reported that greater resilience is associated with problem-based coping styles (i.e., reducing or eliminating stressors). Furthermore, individuals with resilience used fewer avoidance coping strategies. Cowden [39] also reported that individuals with emotional intelligence (an important construct in ER) have high resilience for effective coping. Therefore, individuals with resilience are more likely to adopt effective coping strategies. This is because of their ability to regulate their emotions. In particular, sports-related studies demonstrated that some adaptive strategies (e.g. reassessment $\&$ acceptance) reduce negative affect after gambling/watching a sad movie, and accelerate post-event recovery $[33,40]$.

An essential issue in the current literature on resilience is whether all outcomes related to resilience are resulting from this construct or other psychological mechanisms should be considered. Recently, growing steps were taken to clarify this issue. Several studies that have used the statistical mediation modeling method have reported the indirect effects of resilience concerning well-being in students, motivation in athletes, and coping effectiveness in athletes [39, 41, 42]. These findings emphasize the explanatory role of resilience in achieving positive psychological results. However, some research determined the role of resilience in change, especially when the results are negative.

In the study of Mutz et al. [35], the negative relationship between resilience and depression was mediated by suppression as an ER strategy. In another study on cyclists, Jones and Parker [43] reported mindfulness as a minor mediator in the relationship between resilience and catastrophizing. Cowden et al. [24] declared that self-forgiveness mediated resilience, self-criticism, and anger after competing in tennis athletes. These studies pay particular attention to how individuals with resilience seem to approach and respond to problems, difficulties, and failures.

Two other factors that may explain the mechanisms by which resilience reduces adverse responses, and individuals with this trait are more likely to return to the team following competitive failures and breaks, are selfcompassion and ER. In a qualitative study, female swimmers reported that self-compassion plays a crucial role in building resilience in difficult situations [26]. A longitudinal study also found a positive relationship between challenge assessment, adaptive ER, and positive emotion. There was also a positive relationship between threat/loss assessments, maladaptive ER, and negative emotion. Moreover, ER strategies play a mediating role between evaluations and emotions [44]. Besides, resilience has been conceptualized as an important trait that affects a subject's assessment of difficult situations, as a challenge. In other words, failure, poor performance, or individual mistakes are inherent in sports experiences, even for the most elite.

It is impossible for athletes to always be able to avoid the unpleasant thoughts and emotions that provoke them. Instead, athletes with resilience are likely more skilled (a) to have more evaluations of the events as a challenge and opportunity for self-improvement; (b) to correct performance failures that have led to self-criticism and self-condemnation, and (c) to control negative emotions through self-regulatory processes (e.g., emotional control) [24, 35, 45]. Thus, athletes with resilience may be skilled in regulating self-destructive emotions, as an important feature of self-compassion and cognitive ER, i.e., very useful for psychological well-being [6, 46]. Therefore, for athletes with resilience to experience less negative affect, self-compassion, and ER are 
suggested as facilitators of this process. Thus, the current study aimed to investigate the relationship between resilience and negative affect by the mediating role of self-compassion and ER. Understanding this will be even more important in martial arts league competitions where the athlete may have several competitions during the day and require failure management and maintaining psychological readiness for optimal performance.

\section{Materials and Methods}

Among all martial artists (Taekwondo, Karate, Judo, and Wushu) who were active in the national league competitions in 2019, according to the proposal of Diamantopoulos and Siguaw [47] as using 200 individuals as the minimum reliable sample size for structural equations modeling studies, a total of 286 martial artists (191 males \& 95 females, Mean \pm SD age: 38.23 \pm 7.36 y) participated in this study. All study participants had a Mean $\pm S D$ of $13.17 \pm 5.72$ years of sports experience.

The following instruments were used in this research to collect the necessary data

Sports Mental Toughness Questionnaire (SMTQ): The Persian version of the 14-item SMTQ [36] was used, which includes 3 subscales of confidence (6 items), constancy ( 4 items), and control (4 items). Besides, it is scored based on a five-point Likert-type scale, from strongly disagree (1) to strongly agree (5). The construct validity and reliability of this tool have been confirmed in the Iranian population (Cronbach's alpha coefficient=0.83) [48].

Positive and Negative Affect Schedule (PANAS): The Persian version of the 10-item PANAS scale [49] was used for measuring negative affect (e.g., worry, sorrow, etc.) based on the five-point Likert-type scale, ranging from very low (1) to very high (5). The construct validity $[50,51]$ and the reliability of this tool in the Iranian population have been confirmed (Cronbach's alpha coefficient=0.85) [50].

Self-Compassion Scale (SCS): The Persian version of the 12-item SCS [52] was used. It has 3 subscales of selfkindness ( 4 items), common humanity (4 items), and mindfulness (4 items). Moreover, it is scored based on a five-point Likert-type scale, ranging from almost never (1) to almost always (5). The construct validity and reliability of this tool have been approved in the Iranian population (Cronbach's alpha coefficient=0.86) [53].
Cognitive Emotion Regulation Questionnaire (CERQ): The Persian version of the 18-item CERQ [32] was used. The CERQ has 9 subscales of self-blame, other-blame, rumination, catastrophizing, positive refocusing, planning, positive reappraisal, putting into perspective, and acceptance. The scale's items are classified under two types of coping strategies; adaptive (10 items) and maladaptive ( 8 items). The construct validity and reliability of this tool have been confirmed in the Iranian population (Cronbach's alpha coefficient for subscales=0.76-0.89) [54].

The researcher gained information on the time and place of the competitions by visiting the federations' websites. The researcher, while coordinating and obtaining permission from the coaches, explained the goals and necessity of the research to the athletes. Furthermore, to observe the ethical points of the research, the study participants provided informed consent and were allowed to withdraw from participation as desired. They were assured that the information obtained from the research would be analyzed as a group and that their personal information would remain strictly confidential. The instructions on how to complete the questionnaires were included with each questionnaire; however, the study participants were requested to seek help from the researcher if they had any questions or concerns about completing the inventories. With the consent of the athletes, the information was obtained in which they reported their emotional state before the competition by completing the Negative Affect Scale, and after the competition, they completed Negative Affect Scale again and other questionnaires (resilience, self-compassion, \& ER) and the average time to complete the questionnaires equaled 10-15 minutes.

After collecting the necessary data, descriptive statistics (Mean $\pm S D$, internal consistency, Pearson correlation coefficient) were used to analyze the collected data. Furthermore, path analysis was used for more complex analyzes concerning the causal structure between the research variables and the existence of mediating variables of self-compassion and ER; the criterion variable for resilience, and the predictor of negative emotional reactions to failure. Statistical analyses were performed using SPSS v. 26 and AMOS v. 22. The level of statistical significance in all analyses was determined to be 0.05 .

\section{Results}

Table 1 presents the statistical indexes (internal consistency, correlation coefficient, Mean $\pm S D$, minimum, and maximum scores) of the study participants. Before 
Table 1. Correlations and descriptive statistics of the variables

\begin{tabular}{|c|c|c|c|c|c|}
\hline Characteristics & 1 & 2 & 3 & 4 & 5 \\
\hline 1. Resilience & 1 & & & & \\
\hline 2. Self-Compassion & $0.42^{* *}$ & 1 & & & \\
\hline 3. Adaptive ER & $0.33^{* *}$ & $0.18^{* *}$ & 1 & & \\
\hline 4. Maladaptive ER & $-0.27^{* *}$ & $-0.48^{* *}$ & $-0.07^{* *}$ & 1 & \\
\hline 5. Negative emotions & $-0.45^{* *}$ & $-0.54^{* *}$ & $-0.22^{* *}$ & $0.45^{* *}$ & 1 \\
\hline 6. Scores range & $26-70$ & $15-59$ & $20-49$ & $11-38$ & $13-50$ \\
\hline Mean $\pm S D$ & $48.26 \pm 8.25$ & $37.82 \pm 8.00$ & $36.42 \pm 6.50$ & $24.84 \pm 5.63$ & $30.33 \pm 7.73$ \\
\hline Cronbach's alpha coefficient & 0.84 & 0.84 & 0.81 & 0.82 & 0.85 \\
\hline
\end{tabular}

performing the correlation between the research variables, to determine the emotional reactions to the failure, the scores of negative affect scores of the martial artists before the competition (Mean $\pm S D=19.96 \pm 6.24$ ) and after the competition (Mean $\pm S D=30.40 \pm 7.87$ ) were compared using Dependent Samples t-test. The relevant results indicated that failure significantly increased negative affect in the examined marital artists $(P=0.001$, $t=25.86)$ and their scores increased by 10.43 values.

In Table 1, the results of the correlation coefficient revealed that resilience has a significant negative relationship with negative affect $(r=-0.45)$ and maladaptive ER $(r=0.27)$. While the relationship between resilience and self-compassion ( $r=-0.42)$ and adaptive ER ( $r=-0.18)$ is positive. The collected data also signified that selfcompassion ( $r=-0.54)$ and adaptive ER $(r=-0.22)$ were reversely correlated with negative affect; however, there was a negative relationship between maladaptive ER and negative affect $(r=0.45)$. All obtained correlation coefficients between the research variables were significant at the level of 0.01. Additionally, Cronbach's alpha coefficient was acceptable to ensure the internal consistency of the research variables $(\alpha \geq 0.81)$.

Figure 1 analyzes the relationship between the predictor variable (resilience) and the criterion variable (negative affects) as well as mediator variables (self-com-

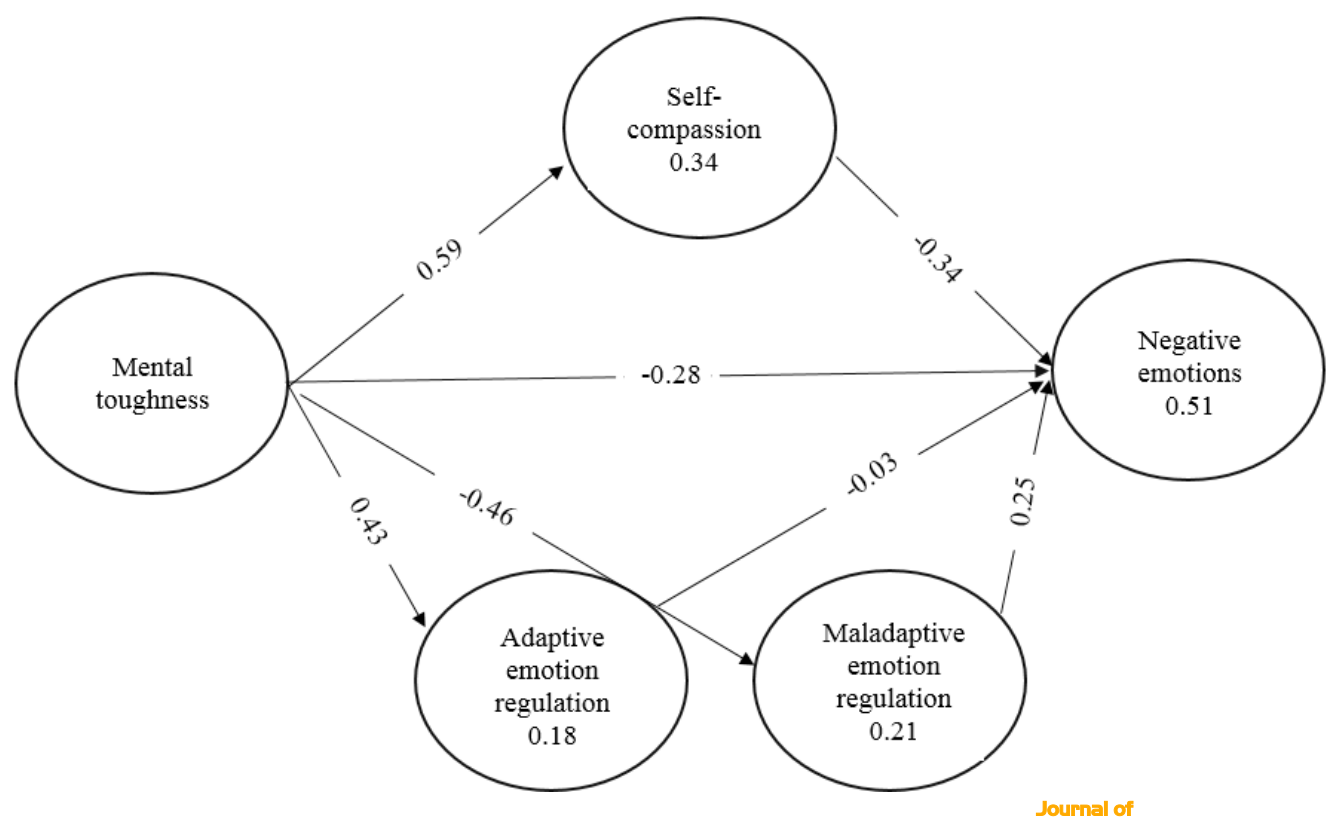

Figure 1. Structural equation modeling model 
Table 2. Estimation of direct, indirect, and total path coefficients

\begin{tabular}{|c|c|c|c|}
\hline Path & Direct Effect & Indirect Effect & Total Effect \\
\hline Resilience $\rightarrow$ Negative emotions & $-0.28^{* * *}$ & $-0.32^{* * *}$ & $-0.60^{* * *}$ \\
\hline Self- compassion $\rightarrow$ Negative emotions & $-0.34^{* * *}$ & & $0.34^{* * *}$ \\
\hline Maladaptive ER $\rightarrow$ Negative emotions & $0.27^{* * *}$ & & $0.27^{* * *}$ \\
\hline Adaptive ER $\rightarrow$ Negative emotions & -0.03 & & -0.03 \\
\hline Resilience $\rightarrow$ Self- compassion & $0.59^{* * *}$ & & $0.59^{* * *}$ \\
\hline Resilience $\rightarrow$ Maladaptive ER & $-0.46^{* * *}$ & & $-0.46^{* * *}$ \\
\hline Resilience $\rightarrow$ Adaptive ER & $0.43^{* * *}$ & & $0.43^{* * *}$ \\
\hline
\end{tabular}

passion \& ER). After performing the path analysis, an experimental and practical model was obtained. The fit indexes obtained from path analysis with the maximum odds method indicated the linearity of the relationships between the variables and the appropriate fit of the model with the data $\left(X^{2} / d f=1.69, C F I=0.92, T L I=0.92\right.$, $\mathrm{IFI}=0.91, \mathrm{RMSEA}=0.05$ ) (Chi Square/degree of freedom ratio=1.69; comparative Fit Index $=0.92$; tucker Lewis index $=0.92$; incremental fit index $=0.91$; root mean square error of approximation=0.05).

According to Figure 1, resilience, self-compassion, and maladaptive ER accounted for a total of $51 \%$ of the variance of negative affect. Resilience alone predicted 34\% of self-compassion changes. Resilience alone predicted $18 \%$ of adaptive ER changes and $21 \%$ of maladaptive ER changes. Table 2 lists the estimation of direct, indirect, and total path coefficients for the research variables.

Table 2 presents the direct effect of resilience on negative affect, with a path coefficient of -0.28 ; the direct effect of narcissism on negative affect, with a path coefficient of -0.34 , the direct effect of maladaptive ER on negative affect, with a path coefficient of 0.27 was significant ( $t>1.96, P \leq 0.01)$, the direct effect of maladaptive ER was not significant on negative affect.

The direct effect of resilience on self-compassion with a path coefficient of 0.59 , the direct effect of resilience on maladaptive ER with path coefficient -0.46 , the direct effect of resilience on maladaptive ER with a path coefficient of 0.43 was significant $(t>1.96, P \leq 0.01)$.

The indirect effect of resilience on negative affect with mediating self-compassion and maladaptive ER with a path coefficient of -0.31 , was significant $(t>1.96 \leq 0.01)$.
However, the indirect effect of resilience on negative affect with the mediation of adaptive ER was not significant.

Based on the current study findings, the hypothetical model of the research for the mediating role of selfcompassion and ER in the relationship between resilience and negative affect to failure was confirmed by empirical evidence.

\section{Discussion}

In this study, the relationship between resilience and emotional reactions to failure in martial artists was investigated. It was also examined whether self-compassion and ER play a mediating role in this relationship. The obtained results suggested that resilience was negatively related to negative affect. Furthermore, the relationship between resilience and negative affect was partially mediated by self-compassion and maladaptive ER; however, the mediating role of adaptive ER was not confirmed.

The finding that higher levels of resilience are associated with fewer negative affect provides important details about the emotional reactions of martial artists with resilience and poor performance. Previous studies in different competitive areas $[25,55]$ and regardless of win-lose [24, 25], examined the relationship between resilience and some emotions. Instead, we focused on emotional reactions in failure conditions. The collected results supported the common conceptualization of athletes with resilience, including emotional stability and composure [46]; although this is the first study to provide evidence of this kind concerning negative emotional responses to failure. Resilience includes the ability to accept the inevitable and unpleasant characteristics of competition [20]; thus, acknowledging the odds of poor performance may help these athletes to psychologically 
prepare for mistakes, performance decline, and failure [24]. This awareness might help maintain the ability of goal-oriented focus, avoid error-prone engagement and over rumination, even when poor performance occurs. Therefore, these athletes should focus on the positive points and use their failures as motivation for success. The discovery that martial artists with resilience are less likely to fail may indicate that their self-worth might depend on how they perform.

According to prior research [56], self-esteem depends on several areas of self-perception (e.g. athletic competence), i.e., affected by the athlete's self-efficacy respecting each of them. Athletes with resilience are thought to have a broad range of perceived competencies, such as athletic success and coping with stress $[19,20]$. These are combined for self-perceived competencies and seem to protect against the negative effects of failure.

The finding that self-compassion plays a minor mediating role in the relationship between resilience and negative affect indicates that low levels of negative affect in resilient martial artists are due to the desire for self-compassion. This is an essential finding because it highlights the role of key psychological mechanisms that have not traditionally been recognized in fostering resilience responses. It is also a sign of how resilient athletes tend to experience less emotion when they experience failure. In particular, negative affect arises from mistakes, shortcomings in standards, and competitive losses [11]. Failure-Induced emotions are reduced by forgiving the behaviors that result from them [24]. Self-Compassion, by providing forgiveness [57], may reduce the types of negative affect in failures. Accordingly, having resilience might not avoid resentful or unpleasant emotions towards oneself; however, it rather indicates a desire for self-compassion and greater forgiveness of one's shortcomings as a form of coping [26, 58]. Moreover, , the increase in anxiety and distress states (fear, worry, panic) when failure may indicate that the individual less perceive their ability to meet future function [59].

Self-Compassion, as an important trait, i.e., activated in difficult situations, like failure reduces functional anxiety [60]. Besides, it is associated with better performance perception [61]. In other words, self-compassion has an optimistic outlook along with the mindfulness [26]; accordingly, it may cause martial artists to focus on the positive points when they fail, to become less immersed in future performance concerns, and to stay motivated to achieve the goal. This finding was in line with those of studies indicating that self-compassion plays an important role in building resilience [26] and is effective in achieving long-term goals [58]. Thus, this study highlighted that self-compassion is an approach by which resilient athletes reduce their negative affect when facing failure and recover faster for optimal performance.

The collected results also reflected that maladaptive ER plays a minor mediating role in the relationship between resilience and negative affect. The present study adds resilience to the current literature. This is because it is the first study to address how individuals with resilience regulate their emotions when they fail. However, these results mean that when martial artists fail in competition and experience negative affect, resilience could be used as a solution to relate to these experiences, which disrupts the problematic circle of negative thoughts and emotions after failure. This is important because maladaptive ER perpetuates negative affect and has serious consequences for athletes' mental health [44]. Our findings were consistent with those of other research reporting that resilience is associated with a high ability to control thoughts $[30,38]$. In addition, another study determined that negative evaluation increases negative affect after the competition with increasing cognitive patterns. However, resilience is a set of attitudes and cognitions that, by positively evaluating difficult situations, conceptualize it as a challenge $[18,45]$. Nevertheless, some research reported a darker aspect of resilience. For example, individuals with resilience score higher on narcissism [62]. This trait is related to the claim of success responsibility by resilient individuals and that they place the blame for failures on others [63].

The data identified that when failing, resilient individuals use less reprimanding others for regulating their emotions, which indicates the high acceptance of these individuals. Resilience includes the ability to accept the inevitable and unpleasant features of competition [20]; thus, this helps athletes prepare themselves psychologically for mistakes, poor performance, and failure [24]. This awareness promotes the ability to maintain goaloriented focus, avoid error-prone engagement, and avoid over- rumination on inadequate performance, and reduce negative affect when failing.

Other results of this study signified that maladaptive ER does not present a minor mediating role in the relationship between resilience and negative affect; therefore, low levels of negative affect among resilient martial artists is not dependent on using cognitive adaptive regulation strategies. Previous studies specified that the effectiveness of using adaptive ER strategies to regulate emotion depends on the context [35]. The resilience (as 
a contextual factor) in the athlete is conceptually related to the athlete's perception of the controllability of the situation; therefore, it may explain the lack of a significant effect on mediation. Troy et al. [33] stated that the reassessment strategy is ineffective when applied in controllable situations, and even when negative affect intensifies, the reassessment strategy tends to be avoided [64]. In the component of developing the athlete's perspective by attempting to minimize the situation (e.g., there are worse things in life), they try to reduce the effect of the event; while league competitions are an essential event for martial artists in Iran, and the failure not only affects the athlete but also causes a change in the position of a team and sometimes the elimination of a team from the competition. Additionally, resilient athletes, instead of downplaying and underestimating, consider the situation as a challenge that most athletes experience in life. Therefore, resilient athletes who have the trait of self-compassion may not use the putting into a perspective strategy to adapt to failure in this field (league competitions). Individuals with resilience cope with the failure with a balanced and open mind (mindfulness) instead of distancing themselves from the stressful situation and moving toward a positive event (reassessment strategy) [26, 32]; therefore, such cognitive strategies (e.g., refocusing) may not be effective for them in the event of failure. Accordingly, the mere presence of a resilience trait in the athlete may be sufficient. Moreover, refocusing on planning indicates that the individual is using previous experiences for the next step [32]. Therefore, it may be used where there is a chance again [65]. The martial artists' readiness for the next match might be affected by their previous competitive result; therefore, the commitment to rescheduling might be reduced, as they may perceive that they do not fit into the team's arrangement. However, this finding needs to be further investigated to determine whether Individuals with resilience use this strategy in the case of they have a second chance for competition.

\section{Conclusion}

Resilience was associated with less maladaptive emotion regulation, but more adaptive ER and self-compassion. Mediation analysis suggested that resilience may be complemented by self-compassion and ER, a process that reduces or minimizes the negative thoughts and emotions that athletes with resilience have about themselves. Beyond providing insight into the types of emotional reactions, athletes who have different levels of resilience experience in response to failure and poor performance, self-compassion, and ER may be an alter- native pathway. Their interventions can help strengthen the resilience responses when athletes make certain mistakes, perform poorly, and do not succeed in the competition, to recover from these conditions at the soonest possible.

This study first examined the relationship between resilience and negative emotional responses to failure, and whether self-compassion and ER mediate these effects. These findings provided insight into how mentally tough athletes respond to failing situations and difficult situations such as failure. However, the obtained results should be interpreted in light of their limitations.

This study was cross-sectional; therefore, no causal conclusion should be inferred. Although the data support our hypothetical model, other theoretical models may also be consistent with the data. Longitudinal and experimental research is needed for further support.

Moreover, each psychological variable was measured from the perspective of the martial artists and according to the cognitive, emotional, and behavioral tendencies common in league matches. Based on evidence that supports intrapersonal situational variability in resilience [22], whether these findings are replicated in specific situations requires further investigation.

Future research is also required to explore if martial artists who have been rated higher concerning self-compassion, ER, and resilience may perform better or not. And what will be the process of determining the patterns of mental improvement of athletes and their subsequent performance with different degrees of resilience?

Finally, in this study, resilience was measured with a multidimensional approach. Despite the general agreement that resilience is a multidimensional construct, some studies have recently considered resilience as a one-dimensional structure [19]. Future research is necessary to understand if this approach may provide additional information on the role of this construct in the event of failure.

\section{Ethical Considerations}

\section{Compliance with ethical guidelines}

The Ethics Committee of Research at the University of Tehran, Department of Sport Psychology approved the current study (Etical code: IR.UT.SPORT.REC.1398.064). 
Funding

This research did not receive any grant from funding agencies in the public, commercial, or non-profit sectors.

\section{Authors' contributions}

All authors equally contributed to preparing this article.

\section{Conflict of interest}

The authors declared no conflict of interest.

\section{References}

[1] Davis IV H, Liotti M, Ngan ET, Woodward TS, Van Snellenberg JX van Anders SM, et al. FMRI BOLD signal changes in elite swimmers while viewing videos of personal failure. Brain Imaging and Behavior. 2008; 2(2):84-93. [DOI:10.1007/s11682-007-9016-x]

[2] Juster RP, McEwen BS, Lupien SJ. Allostatic load biomarkers of chronic stress and impact on health and cognition. Neuroscience \& Biobehavioral Reviews. 2010; 35(1):2-16. [DOI:10.1016/j.neubiorev.2009.10.002] [PMID]

[3] Reis NA, Kowalski KC, Ferguson L, Sabiston CM, Sedgwick WA, Crockerc PRE. Self-compassion and women athletes' responses to emotionally difficult sport situations: An evaluation of a brief induction. Psychology of Sport and Exercise, 2015; 16(Pt 3):18-25. [DOI:10.1016/j.psychsport.2014.08.011]

[4] Baillie PHF, Davis IV H, Ogilvie BC. Working with elite athletes In: Van Raalte JL, Brewer JL, editors. Exploring Sport and Exercise Psychology. Washington, DC: American Psychological Association; 2014. pp. 401-425. [DOI:10.1037/14251-018]

[5] Hammond T, Gialloreto C, Kubas H, Hap Davis 4th H. The prevalence of failure-based depression among elite athletes. Clinical Journal of Sport Medicine. 2013; 23(4):273-7. [DOI:10.1097/ JSM.0b013e318287b870] [PMID]

[6] Ferguson L, Kowalski KC, Mack DE, Sabiston CM. Self-compassion and eudaimonic well-being during emotionally difficult times in sport. Journal of Happiness Studies. 2015; 16(5):1263-80. [DOI:10.1007/s10902-014-9558-8]

[7] Jones MV, Sheffield D. The impact of game outcome on the wellbeing of athletes. International Journal of Sport and Exercise Psychology. 2007; 5(1):54-65. [DOI:10.1080/1612197X.2008.9671812]

[8] Brunstein J. Motivation and performance following failure: The effortful pursuit of self-defining goals. Applied Psychology. 2000; 49(3):340-56. [DOI:10.1111/1464-0597.00019]

[9] Lizmore MR, Dunn JGH, Dunn JC, Hill AP. Perfectionism and per formance following failure in a competitive golf-putting task. Psychology of Sport and Exercise. 2019; 45:101582. [DOI:10.1016/j. psychsport.2019.101582

[10] Seligman MEP, Nolen-Hoeksema S, Thornton N, Thornton KM. Explanatory style as a mechanism of disappointing ath- letic performance. Psychological Science. 1990; 1(2):143-6 [DOI:10.1111/j.1467-9280.1990.tb00084.x ]

[11] Ceccarelli LA, Giuliano RJ, Glazebrook CM, Strachan SM. Selfcompassion and psycho-physiological recovery from recalled sport failure. Frontiers in Psychology. 2019; 10:1564. [DOI:10.3389/fpsyg.2019.01564] [PMID] [PMCID]

[12] Sagar SS, Busch BK, Jowett S. Success and failure, fear of failure, and coping responses of adolescent academy football players. Journal of Applied Sport Psychology. 2010; 22(2):213-30. [DOI:10.1080/10413201003664962]

[13] Sutherland LM, Kowalski KC, Ferguson L, Sabiston CM, Sedgwick WA, Crocker PRE. Narratives of young women athletes' experiences of emotional pain and self-compassion. Qualitative Research in Sport, Exercise and Health. 2014; 6(4):499-516. [DOI:10.1080/215 9676X.2014.888587

[14] Sagar SS, Lavallee D, Spray CM. Why young elite athletes fear failure: Consequences of failure. Journal of Sports Sciences, 2007 25(11):1171-84. [DOI:10.1080/02640410601040093] [PMID]

[15] Tenenbaum G, Basevitch I, Gershgoren L, Filho E. Emotions-decision-making in sport: Theoretical conceptualization and experimental evidence. International Journal of Sport and Exercise Psychology. 2013; 11(2):151-68. [DOI:10.1080/1612197X.2013.773687]

[16] Fletcher D, Sarkar M. A grounded theory of psychological resilience in Olympic champions. Psychology of Sport and Exercise. 2012; 13(5):669-78. [DOI:10.1016/j.psychsport.2012.04.007]

[17] Lizmore MR, Dunn JG, Dunn JC. Perfectionistic strivings, perfectionistic concerns, and reactions to poor personal performances among intercollegiate athletes. Psychology of Sport and Exercise. 2017; 33:75-84. [DOI:10.1016/j.psychsport.2017.07.010]

[18] Gucciardi DF, Gordon S, Dimmock JA. Development and preliminary validation of a mental toughness inventory for Australian football. Psychology of Sport and Exercise. 2009; 10(1):201-9. [DOI:10.1016/j.psychsport.2008.07.011]

[19] Gucciardi DF, Hanton S, Gordon S, Mallett CJ, Temby P. The concept of mental toughness: Tests of dimensionality, nomological network, and traitness. Journal of Personality. 2015; 83(1):26-44 [DOI:10.1111/jopy.12079] [PMID]

[20] Jones G, Hanton S, Connaughton D. A framework of menta toughness in the world's best performers. The Sport Psychologist. 2007; 21(2):243-64. [DOI:10.1123/tsp.21.2.243]

[21] Crust L. A review and conceptual re-examination of mental toughness: Implications for future researchers. Personality and Individua Differences. 2008; 45(7):576-83. [DOI:10.1016/j.paid.2008.07.005]

[22] Weinberg R, Butt J, Mellano K, Harmison R. The stability of mental toughness across situations: Taking a social-cognitive approach. International Journal of Sport Psychology. 2017; 48(3):280-302. [DOI:10.7352/IJSP.2017.48.280]

[23] Clough P, Earle K, Sewell D. Mental toughness: The concept and its measurement. Solutions in Sport Psychology. 2002; 32-43. https:// www.researchgate.net/publication/nd its nt

[24] Cowden RG, Crust R, Joynt S, Hook J, Worthington Jr EL. How do mentally tough athletes overcome self-directed anger, shame, and criticism? A self-forgiveness mediation analysis. International Journal of Sport Psychology. 2018; 49(4):327-48. [DOI:10.7352/ IJSP.2018.49.327] 
[25] Mahoney JW, Gucciardi DF, Ntoumanis N, Mallett CJ. Mental toughness in sport: Motivational antecedents and associations with performance and psychological health. Journal of Sport and Exercise Psychology. 2014; 36(3):281-92. [DOI:10.1123/jsep.2013 0260] [PMID]

[26] Wilson D, Bennett EV, Mosewich AD, Faulkner GE, Crocker PRE. The zipper effect: Exploring the interrelationship of mental toughness and self-compassion among Canadian elite women athletes. Psychology of Sport and Exercise. 2019; 40:61-70. [DOI:10.1016/j. psychsport.2018.09.006]

[27] Neff K. Self-compassion: An alternative conceptualization of a healthy attitude toward oneself. Self and Identity. 2003. 2(2):85101. [DOI:10.1080/15298860309032]

[28] Zhang JW, Chen S. Self-compassion promotes personal improvement from regret experiences via acceptance. Personality and Social Psychology Bulletin. 2016; 42(2):244-58. [DOI:10.1177/0146167215623271] [PMID]

[29] Mohebi M, Sahar Z. [The relationship between mental toughness and self-compassion in elite and non-elite adolescent taekwondo athletes (Persian)]. Journal of Motor and Behavioral Sciences. 2019; 2(1):21-31. http://www.jmbs.ir/article_91801.html

[30] Crust L, Azadi K. Mental toughness and athletes' use of psychological strategies. European Journal of Sport Science. 2010; 10(1):4351. [DOI:10.1080/17461390903049972]

[31] Gross JJ. Emotion regulation: Current status and future prospects. Psychological Inquiry. 2015; 26(1):1-26. [DOI:10.1080/1047 840X.2014.940781]

[32] Garnefski N, Kraaij V. Cognitive Emotion Regulation Questionnairedevelopment of a short 18-item version (CERQ-short). Personality and Individual Differences. 2006; 41(6):1045-53. [DOI:10.1016/j. paid.2006.04.010]

[33] Troy AS, Shallcross AJ, Mauss IB. A person-by-situation approach to emotion regulation: Cognitive reappraisal can either help or hurt, depending on the context. Psychological Science. 2013; 24(12):2505-14. [DOI:10.1177/0956797613496434] [PMID]

[34] Mohebi M, Zarei S, Sohbatiha M. [The relationship between Emotion regulation strategies and mental toughness in elite taekwondo athletes (Persian)]. Journal of Sport Psychology Studies. 2017; 6(21):29-42. [DOI:10.22089/SPSYJ.2017.2830.1294]

[35] Mutz J, Clough P, Papageorgiou KA. Do individual differences in emotion regulation mediate the relationship between mental toughness and symptoms of depression? Journal of Individual Differences. 2017; 38(2):71-82. [DOI:10.1027/1614-0001/a000224]

[36] Sheard M, Golby J, van Wersch A. Progress toward construct validation of the Sports Mental Toughness Questionnaire (SMTQ). European Journal of Psychological Assessment. 2009; 25(3):186-93. [DOI:10.1027/1015-5759.25.3.186]

[37] Nicholls A, Perry JL, Jones L, Sanctuary C, Carson F, Clough PJ. The mediating role of mental toughness in sport. The Journal of Sports Medicine and Physical Fitness. 2015; 55(7-8):824-34. [PMID]

[38] Nicholls AR, Polman RCJ, Levy AR, Backhouse SH. Mental toughness, optimism, pessimism, and coping among athletes. Personality and Individual Differences. 2008; 44(5):1182-92. [DOI:10.1016/j. paid.2007.11.011]

[39] Cowden RG. Mental toughness, emotional intelligence, and coping effectiveness: An analysis of construct interrelatedness among high-performing adolescent male athletes. Perceptual and Motor
Skills. 2016; 123(3):737-53. [DOI:10.1177/0031512516666027] [PMID]

[40] Yang Q, Gu R, Tang P, Luo YJ. How does cognitive reappraisal affect the response to gains and losses? Psychophysiology. 2013; 50(11):1094-103. [DOI:10.1111/psyp.12091] [PMID]

[41] Jackman P, Crust L, Swann C. Further examining the relationship between mental toughness and dispositional flow in sport: A mediation analysis. International Journal of Sport Psychology. 2017; 48(3):356-74. [DOI:10.7352/IJSP.2017.48.356]

[42] Jin L, Wang CD. International students' attachment and psychological well-being: The mediation role of mental toughness. Counselling Psychology Quarterly. 2018; 31(1):59-78. [DOI:10.1080/095 15070.2016.1211510]

[43] Jones MI, Parker JK. Mindfulness mediates the relationship between mental toughness and pain catastrophizing in cyclists. European Journal of Sport Science. 2018; 18(6):872-81. [DOI:10.1080/1 7461391.2018.1478450] [PMID]

[44] Saby Y, Pupier Y, Guillet-Descas E, Nicolas M, Martinent G. Longitudinal emotional process among adolescent soccer player in intensive training centre. Journal of Sports Sciences. 2020; 38(1112):1368-79. [DOI:10.1080/02640414.2019.1662538] [PMID]

[45] Levy A, Nicholls A, Polman R. Cognitive appraisals in sport: The direct and moderating role of mental toughness. International Journal of Applied Psychology. 2012; 2(4):71-6. [DOI:10.5923/j. ijap.20120204.05

[46] Gucciardi DF. Mental toughness: progress and prospects. Current Opinion in Psychology. 2017; 16:17-23. [DOI:10.1016/j.copsyc.2017.03.010] [PMID]

[47] Diamantopoulos A, Siguaw JA, Siguaw JA. Introducing LISREL: A guide for the uninitiated. New York: SAGE Publications; 2000. https://books.google.com/books?id=8BYaAAAAYAAJ\&dq

[48] Kashani V, Farokhi A, Kazemnejad A, Shaikh M. [Validity and reliability of the Persian version of Sport Mental Toughness Questionnaire (SMTQ) (Persian)]. Motor Behavior. 2015; 7(20):49-72. https://mbj.ssrc.ac.ir/article_468.html?lang=en

[49] Watson D, Clark LA, Tellegen A. Development and validation of brief measures of positive and negative affect: The PANAS scales. Journal of Personality and Social Psychology. 1988; 54(6):1063-70. [DOI:10.1037/0022-3514.54.6.1063] [PMID]

[50] Bakhshipour A, Dejkam M. [Confirmatory factor analysis of positive and negative emotion scales (Persian)]. Journal of Psychology. 2005; 36(4):351-67. https://www.sid.ir/fa/journal/ViewPaper. aspx?ID=49349

[51] Shokri O, Goodarzi A, Sharifi M. [Testing for factorial invariance of the Farsi version of the positive and negative affect schedule across sexes (Persian)]. Contemporary Psychology. 2014; 9(1):8394. http://bjcp.ir/article-1-495-en.html

[52] Raes F, Pommier E, Neff KD, Van Gucht D. Construction and factorial validation of a short form of the self-compassion scale. Clinical Psychology \& Psychotherapy. 2011; 18(3):250-5. [DOI:10.1002/ cpp.702] [PMID]

[53] Khanjani S, Foroughi AA, Sadeghi K, Bahrainian SA. [Psychometric properties of Iranian version of self-compassion scale (short form) (Persian)]. Pajoohandeh. 2016; 21(5):282-9. http://pajoohande. sbmu.ac.ir/article-1-2292-en.html 
[54] Besharat MA, Bazzazian S. [Psychometric properties of the Cognitive Emotion Regulation Questionnaire in a sample of Iranian population (Persian)]. Advances in Nursing and Midwifery. 2014; 24(84):61-70. https://journals.sbmu.ac.ir/en-jnm/article/ view/7360

[55] Crust L. The relationship between mental toughness and affect intensity. Personality and Individual Differences, 2009; 47(8):959-63. [DOI:10.1016/j.paid.2009.07.023]

[56] Sonstroem RJ, Harlow LL, Josephs L. Exercise and self-esteem Validity of model expansion and exercise associations. Journal of Sport and Exercise Psychology. 1994; 16(1):29-42. [DOI:10.1123/ jsep.16.1.29]

[57] Cleare S, Gumley A, O'Connor RC. Self-compassion, self-forgiveness, suicidal ideation, and self-harm: A systematic review. Clinical Psychology \& Psychotherapy. 2019; 26(5):511-30. [DOI:10.1002/ cpp.2372] [PMID]

[58] Mosewich AD, Sabiston CM, Kowalski KC, Gaudreau P, Crocker PRE. Self-compassion in the stress process in women athletes. Sport Psychologist. 2019; 33(1):23-34. [DOI:10.1123/tsp.2017-0094]

[59] Vast RL, Young RL, Thomas PR. Emotions in sport: Perceived ef fects on attention, concentration, and performance. Australian Psychologist. 2010; 45(2):132-40. [DOI:10.1080/00050060903261538]

[60] Mohebi M, Gharayagh Zandi A, Zarei S, Gharayagh Zandi H. Selfcompassion and pre-competition anxiety among martial arts students. Journal of Exercise Science and Medicine. 2020; 11(2):97104. https://jsmed.ut.ac.ir/article_77696.html

[61] Killham ME, Mosewich AD, Mack DE, Gunnell KE, Ferguson L. Women athletes' self-compassion, self-criticism, and perceived sport performance. Sport, Exercise, and Performance Psychology. 2018; 7(3):297-307. [DOI:10.1037/spy0000127]

[62] Papageorgiou KA, Malanchini M, Denovan A, Clough PJ, Shakeshaft $\mathrm{N}$, Schofield $\mathrm{K}$, et al., Longitudinal associations between narcissism, mental toughness and school achievement. Personality and Individual Differences. 2018; 131:105-10. [DOI:10.1016/j. paid.2018.04.024]

[63] Campbell WK, Reeder GD, Sedikides C, Elliot AJ. Narcissism and comparative self-enhancement strategies. Journal of Research in Personality. 2000; 34(3):329-47. [DOI:10.1006/jrpe.2000.2282]

[64] Wolgast M, Lundh LG, Viborg G. Cognitive reappraisal and acceptance: An experimental comparison of two emotion regulation strategies. Behaviour Research and Therapy. 2011; 49(12):858-66. [DOI:10.1016/j.brat.2011.09.011] [PMID]

[65] Sakakibara R, Endo T. Cognitive appraisal as a predictor of cognitive emotion regulation choice. Japanese Psychological Research. 2016; 58(2):175-85. [DOI:10.1111/jpr.12098] 
This Page Intentionally Left Blank 